\title{
Scientific and methodological bases of rational design of hoisting-and-transport machines metal structures
}

\author{
Yurii Sagirov ${ }^{1}$, Viktor Artiukh², Vladlen Mazur ${ }^{3}$, Maxim Aleksandrovskiy ${ }^{4}$ \\ ${ }^{1}$ Pryazovskyi State Technical University, Universytets'ka, 7, Mariupol, 87500, Ukraine \\ ${ }^{2}$ Peter the Great St. Petersburg Polytechnic University, Polytechnicheskaya, 29, St.Petersburg, \\ 195251, Russia \\ ${ }^{3}$ LLC 'Saint-Petersburg Electrotechnical Company’, Pushkin, Parkovaya str., 56, St.Petersburg, \\ 196603, Russia \\ ${ }^{4}$ Moscow State University of Civil Engineering, 26, Yaroslavskoeshosse, 129337, Moscow, Russia
}

\begin{abstract}
Purpose of this paper is to improve parameters of metal structures elements of hoisting-and-transport machines (HTMs) by means of systematic approach to study changes of their stress-strain state during design or usage stage. Subject of the study is pattern of changes in distribution and values of stresses in elements of metal structures of HTMs depending on the structural and parametric characteristics. Design methodology of metal structures of HTMs on the basis of a portal crane is proposed, it is based on strength calculations using methods of allowable stresses and FEM, 3D computer simulation, system analysis of the stressstrain state and structural-parametric synthesis. Results of modeling of loading state and calculations of the portal crane metal structures on strength by FEM in CAD/CAE system, analysis of their stress-strain state, structuralparametric synthesis are presented. Recommendations on practical application of the results are given. Possible ways of further development of proposed solutions are identified.
\end{abstract}

\section{Introduction}

One of priority ways of science and technique development is energy efficiency and environmental management. Practice of design and usage of HTMs shows that structural and parametric synthesis of metal structures has a significant impact on their technical and operational properties. Durability and reliability of mechanisms of crane depend on properties of its metal structures. Metal structures are the most responsible and expensive elements of HTMs. Therefore, creation of rational structural schemes with proper values of their geometric parameters is important task [1-9].

For metal structures under loads optimization approach to design is the most effective because even relatively small decrease in their weight and dimensions leads to significant savings in labor, material and financial resources during design and operation of HTMs. FEM

*Corresponding author: $\underline{\text { artiukh@mail.ru }}$ 
is widely used for strength calculations and optimization of HTMs elements [10-13]. It is implemented in $\mathrm{CAD} / \mathrm{CAE}$ environment that allows to:

- consider entire metal structure without breaking it into elements;

- increase accuracy of calculations;

- obtain real pictures of stress-strain state of whole metal structure;

- conduct repeated studies using developed model.

\section{Formulation of task}

During operation of HTMs (including portal cranes) defects quite often arise (fractures in places of elements joints and near welding seals of ribs fastening, fractures in base metal, stratification of edges of base metal, etc.) in metal structures under loads. Moreover, defects can appear in fairly new (3-5 years of operation) machines. There can be many reasons for such phenomena which can be investigated through detailed analysis of stress-strain state, e.g. not always successful decisions made during design, operating conditions. In each case they can be different or combined. There is a need for repairs which are not always effective enough because there are cases when defects are formed repeatedly. Improving operational reliability of HTMs by clarifying existing and developing new methodologies for calculating their metal structures is actual scientific and technical task.

From our point of view, both repair measures and adoption of constructive decisions during design (determination of geometric parameters) should be based on analysis of stressstrain state of metal structures and their elements, strength calculations. Nowadays, it is possible due to usage of computers, FEM and CAD/CAE systems.

Analysis of existing methods of design and optimization of metal structures including HTMs metal structures was made earlier [10]. This method is used in more applications. Possible ways of their development and improvement were identified and it was noted that traditional strength calculations of crane metal structures are based on assumption of flat scheme of their work while their elements work as spatial systems. Nowadays, need for breaking down into flat elements and in calculation of isolated large units of metal structures is gradually disappearing. At the same time, there are no methodologies that would prescribe sequence of models development, adoption of design schemes, requirements for calculations and results obtained during design of HTMs metal structures using FEM and CAD/CAE systems. Promising direction is usage of elements of topological optimization method during design of metal structures which is quite common [14-19].

\section{Objectives of this paper}

Purpose of this paper is to improve parameters of HTMs metal structures using a systematic approach to study of changes in stress-strain states at stage of their design or operation. Design methodology of metal structures of HTMs on the basis of a portal crane (refer to fig. 1) is proposed based on strength calculations using methods of allowable stresses and FEM, 3D computer simulation, system analysis of stress-strain state and structuralparametric synthesis. 


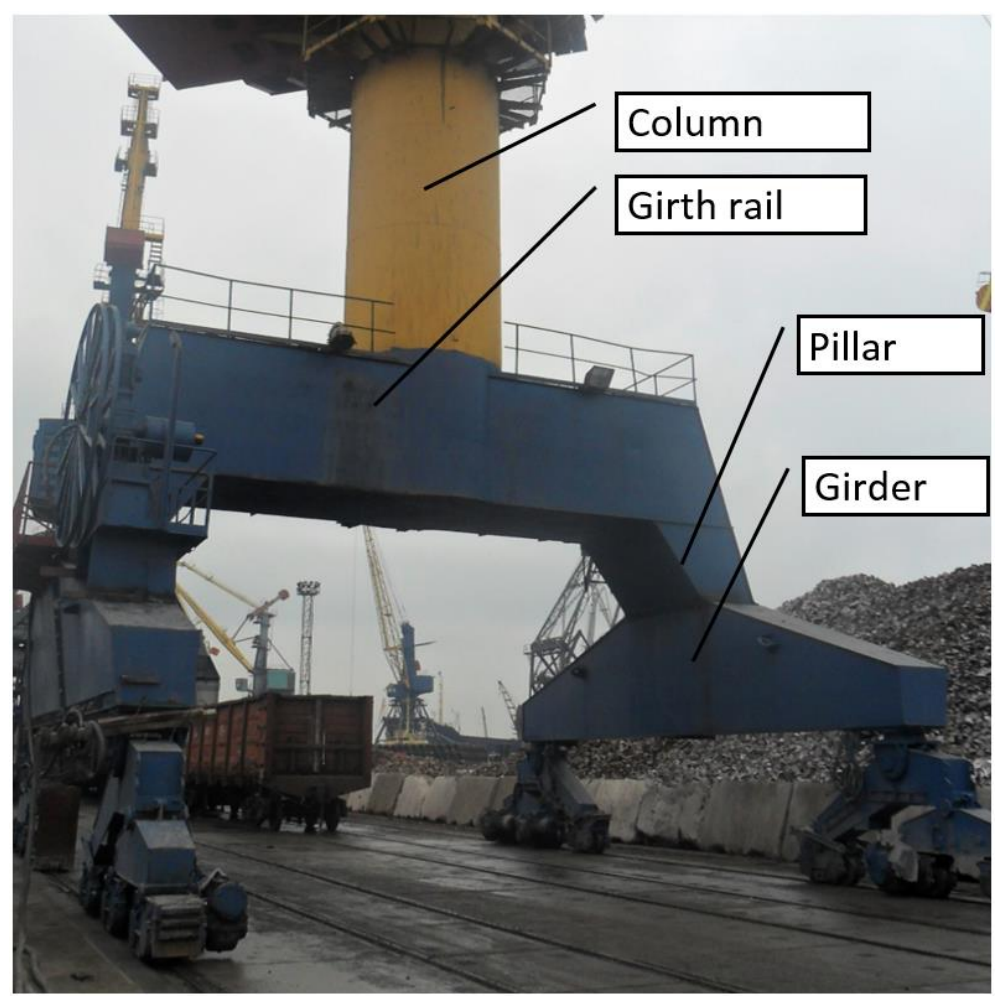

Fig. 1. Elements of the portal crane and their accepted designations.

Subject of the study is pattern of changes in distribution and values of stresses in the elements of the HTM metal structures depending on structural and parametric characteristics.

\section{Materials and methods}

Calculation by FEM was performed to determine actual and further analysis of stress-strain state of the metal structures of portal of the portal crane. Design scheme (refer to fig. 2 [13]) was adopted earlier taking into account well-known recommendations and data on design of metal structures of portal cranes [11]. Design loads and their combinations were taken in accordance with standards for calculating metal structures of portal cranes. Calculation case II (determination of strength of metal structures) took into account maximum (ultimate) working load which includes maximum dynamic loads that occur during sudden starts and emergency braking of mechanisms, sudden turn on of electric current and maximum values of wind load of operating state in addition to loads from own weight and nominal weight of load and load gripping device.

Taking into account geometrical parameters of crane and acting loads a spatial soliddeformed model (1:1 scale) of portal of portal crane 'Azovets' was developed (refer to fig. 2) [14] (places of application of forces and their direction were saved (refer to fig. 2) [13] to solve this task) and FEM mesh was generated (refer to fig. 3) [13]. Acting loads on the metal structure were determined. 


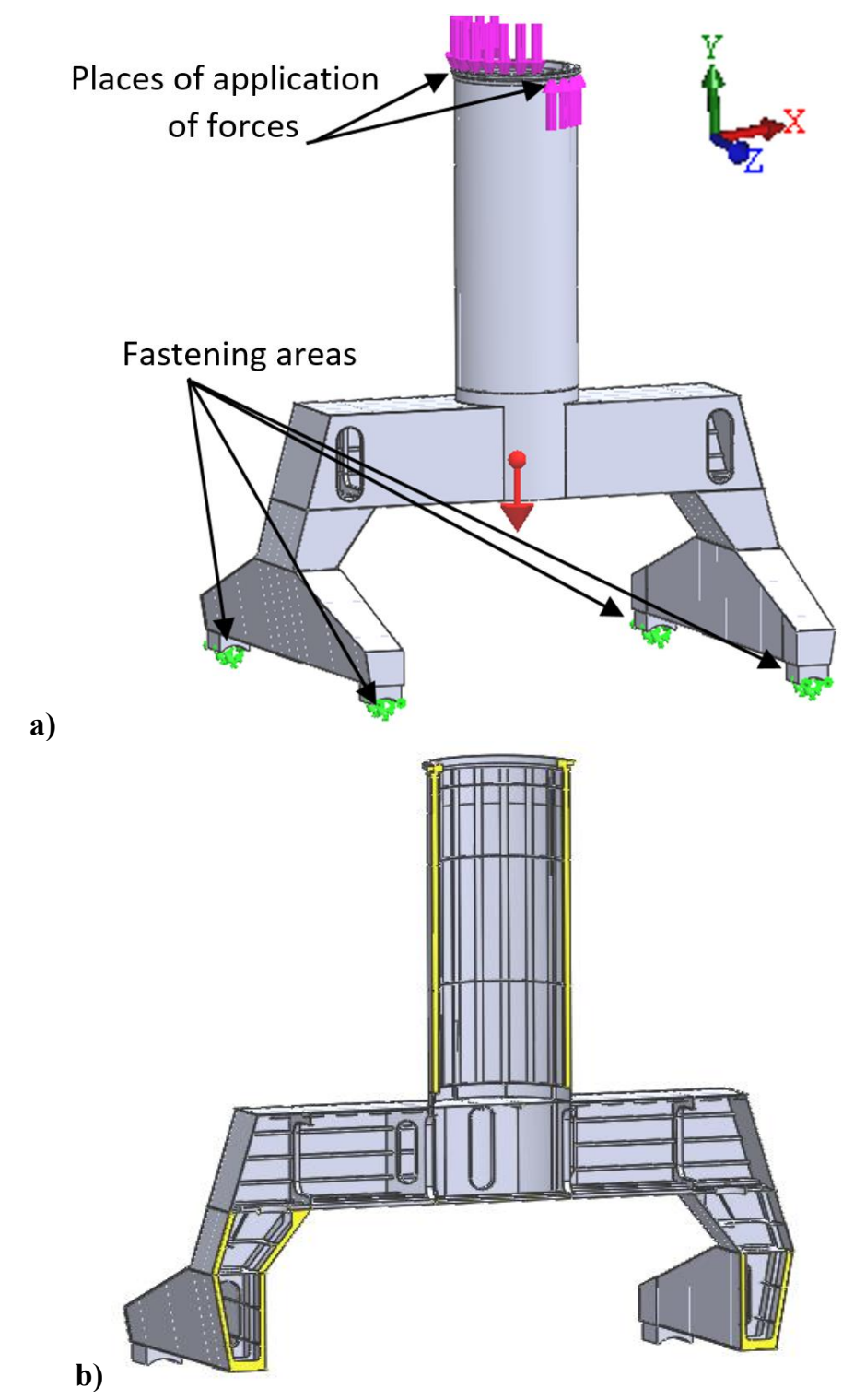

Fig. 2. Developed spatial solid-deformed 3D model: a is a general view, b is a section [13].

Loads were calculated with two loading options.

Option I is when only lifting mechanism works. It is load combination II a:

1. Weight of load is $G$;

2. Coefficient of dynamics is $\psi_{I I}$;

3. Angle of inclination rise is $\alpha_{\text {rise }}$.

Option II is when derricking mechanism and mechanism of turn work. It is load combination II b:

1. Weight of load is $G$.

2. Angles of deviation of ropes from vertical are $a_{I I}, \beta_{I I}$ (in jib swing plane and perpendicular to jib swing plane).

3. Tangent inertia of the jib and trunk when turning the crane are $0.5 \cdot F i j, 0.5 \cdot$ Fit.

4. Inertia forces during change of crane radius are $0.5 \cdot \mathrm{Fir}$. 
5. Wind force of working condition is $P_{I}$.

After checking the model for adequacy a decision was made to use hinge as portal supports for which corresponding elements were modeled (refer to fig. 3). Such solution made it possible to simulate process of possible rotation of running wheel relative to rail as a result of deformation of the portal metal structure that mostly corresponds to behavior of a real object.

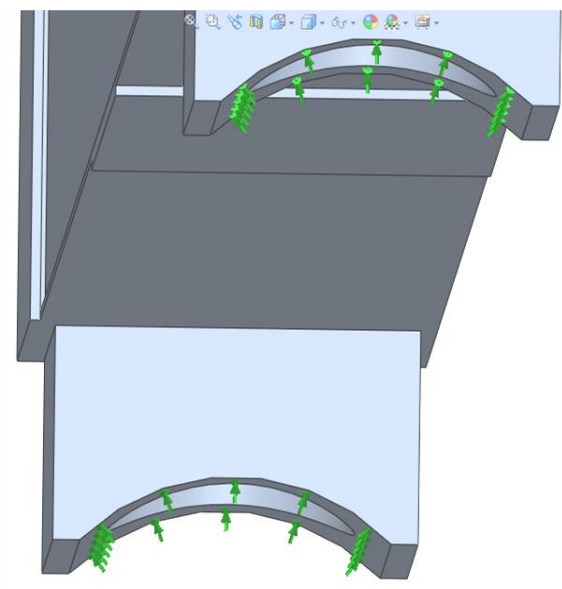

Fig. 3. Places of fastening of the model (increased).

After FEM development of the model mesh was generated [13, fig. 2]. Size of minimum rod is accepted smaller than minimum geometric size in the model.

\section{Results}

As a result of the stress-strain state modeling equivalent stress distribution diagrams, threeplane normal stress diagrams, safety factor distribution diagram, loading flow direction diagram, equivalent stress (von Mises) distribution diagram using 'ISO restriction' tool constraint for two loading options were obtained in the model [13].

Analysis of the stress-strain state of the portal according to the first and second loading cases showed that the first loading variant is the most unfavorable (large stress values). It is allowed to distinguish following elements (refer to fig. 4) which are the most loaded:

1 are internal corners of junction of support and beam;

2 is external sheet of girder above and below entrance opening;

3 are top and side sheets at junction with column;

4 is angular diaphragm inside the girder;

5 are internal angles of junction of beam with balancer of the crane movement.

For more visual display of the most stressed sections of the metal structure a diagram is constructed (refer to fig. 4) using 'ISO restriction' tool which makes it possible not to display sections (make them transparent) stresses of which are less than the set (limit) value. 113MPa is accepted as the ultimate stress value. As a result, diagram was obtained; it is presented on fig. 5 . 


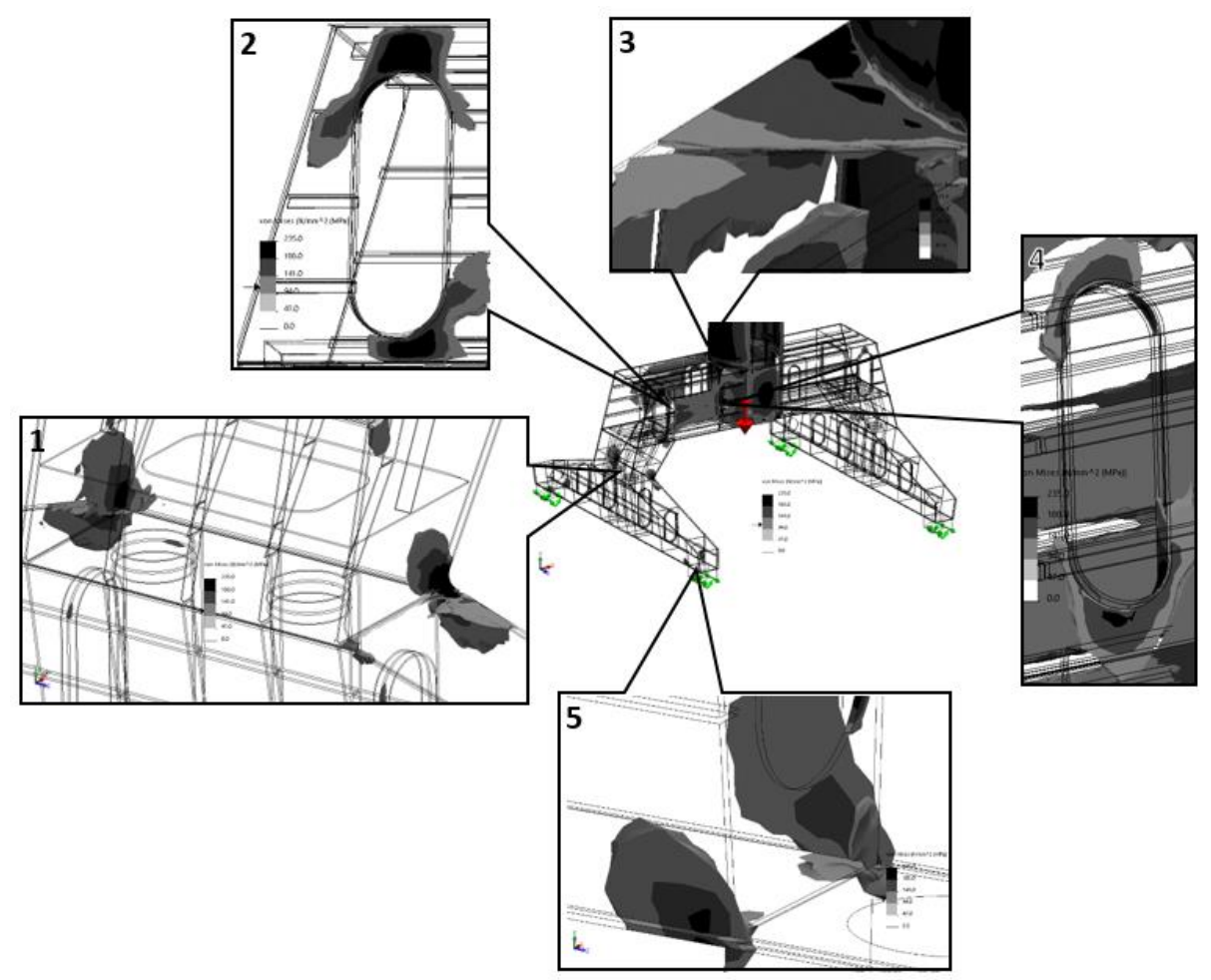

Fig. 4. Display of the most loaded elements after applying 'ISO restriction' tool with limit (113 MPa).

Analysis of documentation of inspection of the crane metal structure showed that in element 1 (refer to fig. 4) following are observed: fracture near welding seal, stratification of base metal along the edge (refer to fig. 5) which completely corresponds to concentration of equivalent stresses obtained during simulation of the loaded state.

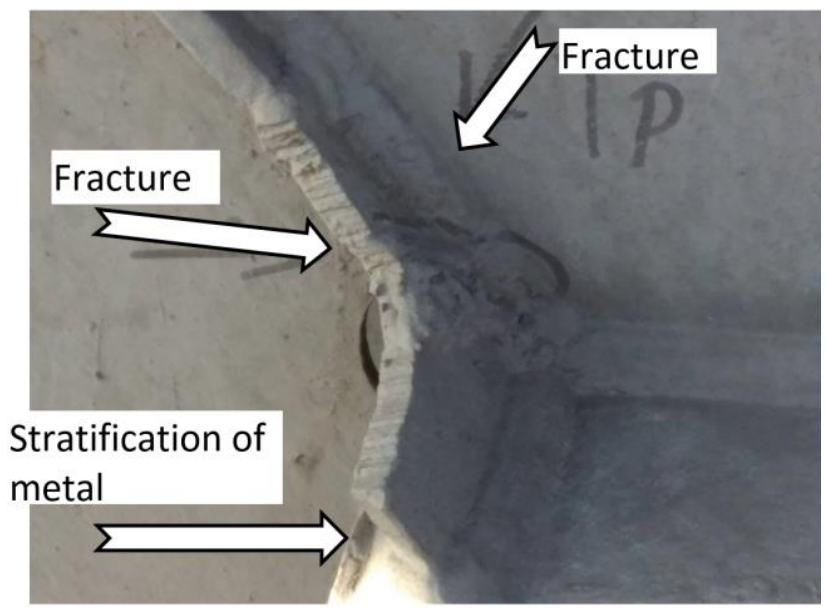

Fig. 5. Photograph of metal part with detected defects.

It should be noted that the stress-strain state is obtained for a particular working condition of the crane, the model is static. This fact can be attributed to the shortcomings of used software because in order to obtain stress-strain state under other conditions (for example, 
other positions of the crane jib relative to rail track) it is necessary to develop a new calculation model and repeat calculation. More information about stress state of the metal elements can be obtained during operation due to numerous possible options of design schemes. Assumption that during operation of the crane some stresses change direction within particular area cannot be discarded.

Above given analysis proves that the stress state of considered area / part is complex, its design is imperfect (which is also confirmed by practice of operation) and requires modernization. During operation of the crane when it is impossible to make significant changes in its design it is not possible to fully use results of structural synthesis which would redistribute material in the structure, change shape of the elements and the stress-strain state, etc.

Analysis also showed that less loaded are:

- lower and upper belts of the girder, internal lower and upper ribs at junction of the girder and the support which have equivalent stress values less than $60 \mathrm{MPa}$;

- internal ribs of the support also have equivalent stress values of less than $60 \mathrm{MPa}$.

Based on the above, two directions for strengthening the portal can be distinguished.

Firstly, it can be aimed at ensuring smoothness of loading flow (uniform distribution of stresses) since stress concentration is a source of fractures and structural failure. Stress concentration arises primarily with a sharp change in thickness (loaded area) of the metal structure. In our case areas with welded shells are ribs, doors installation locations in the girder. Stress concentration is facilitated not only by sharp changes in cross sections but also by presence of sharp angles, grooves, etc. along loading flow path such as angular edges at junction of the support with the beam and the girder with the column.

Secondly, it is strengthening of the most loaded sections of the metal structure by installing pads, additional ribs. Placement of metal in lightly loaded zones is irrational because these zones are not supporting in relation to applied load scheme and design of exist portal.

Numerous modeling and subsequent analysis of the stress-strain state allows to develop optimal design solutions for strengthening the portal. The main focus of development of various design solutions for reinforcement was given to area of connection of the support and the beam, as the most vulnerable.

Following options for reinforcing the metal structure were sequentially modeled (additionally installed elements reinforcing the structure are marked on figures with arrow " $\longleftrightarrow$,).

Option 1. Installation of pad in the most loaded place of side wall of the support.

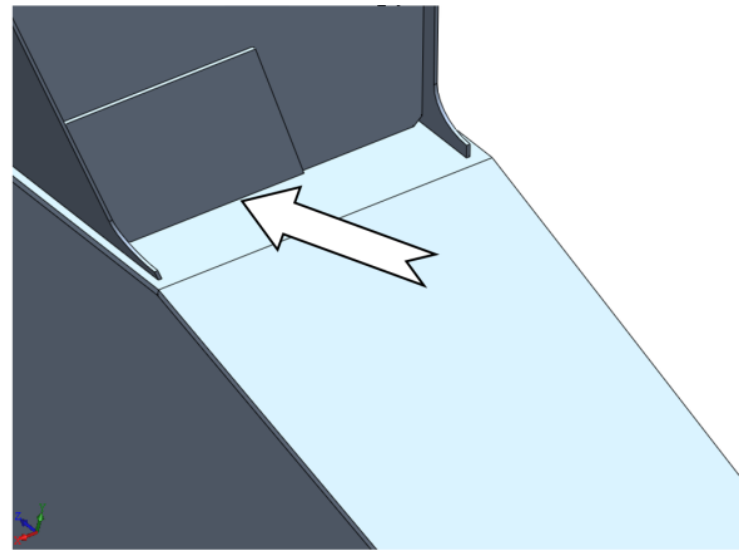

Fig. 6. Portal part with reinforcement according to option 1. 
This solution made it possible to partially reduce the side wall tension as it can be seen on figures below.

a)

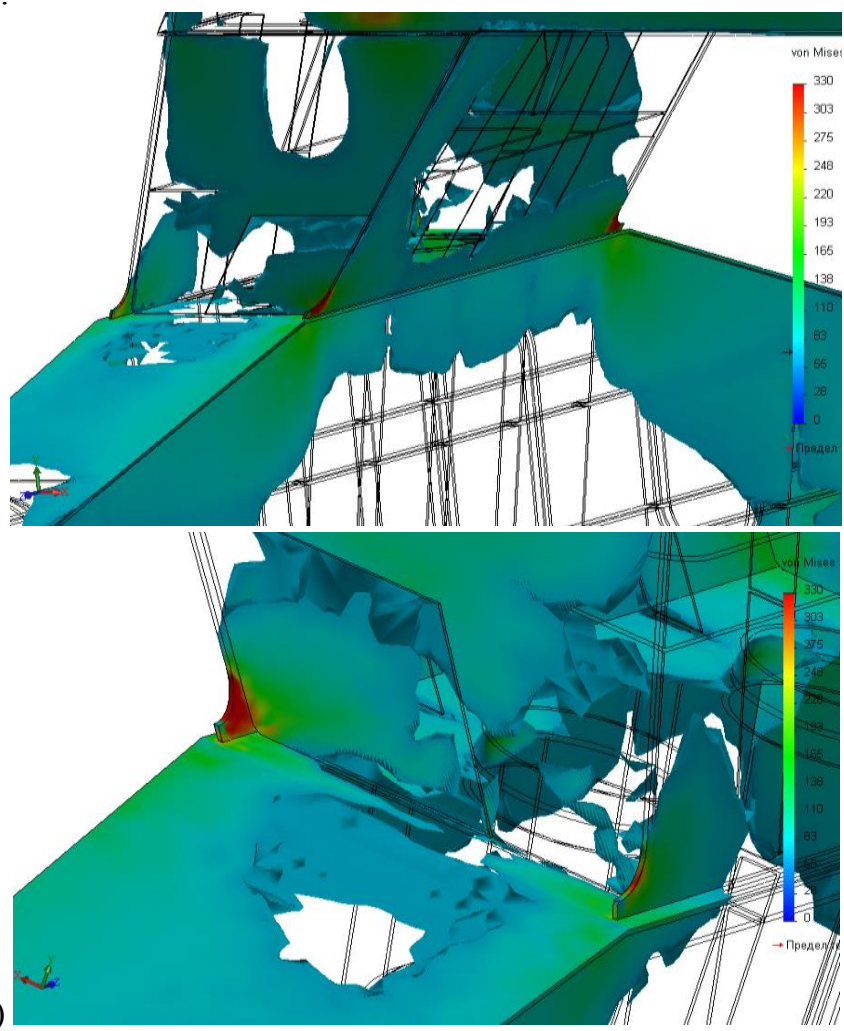

Fig. 7. Diagram of stress distribution taking into account reinforcement according to option 1 with excluded low-loaded elements: $a, b$ are different angles of view.

Installation of the pad does not improve direction of loading flow that can be observed in underloaded section in upper belt of the beam.

Option 2. The next solution is to install a U-shaped pad on inside of the interface between the support and the beam; installation of ribs and stiffener on side surfaces of the support.

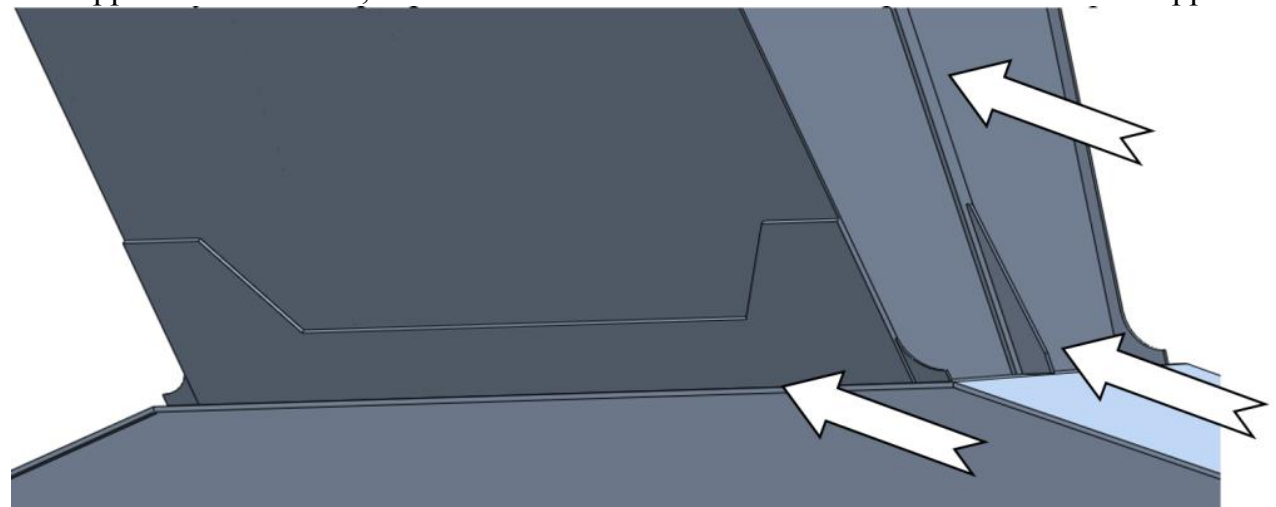

Fig. 8. Portal part with reinforcement according to option 2. 
U-shaped pad on the inner side allowed local redaction of loading of the support wall but it had no effect on change of direction of the loading flow. The rib and the stiffener on the lateral surface of the support made it possible to distribute stresses more evenly and reduce their values by about $10 \%$.

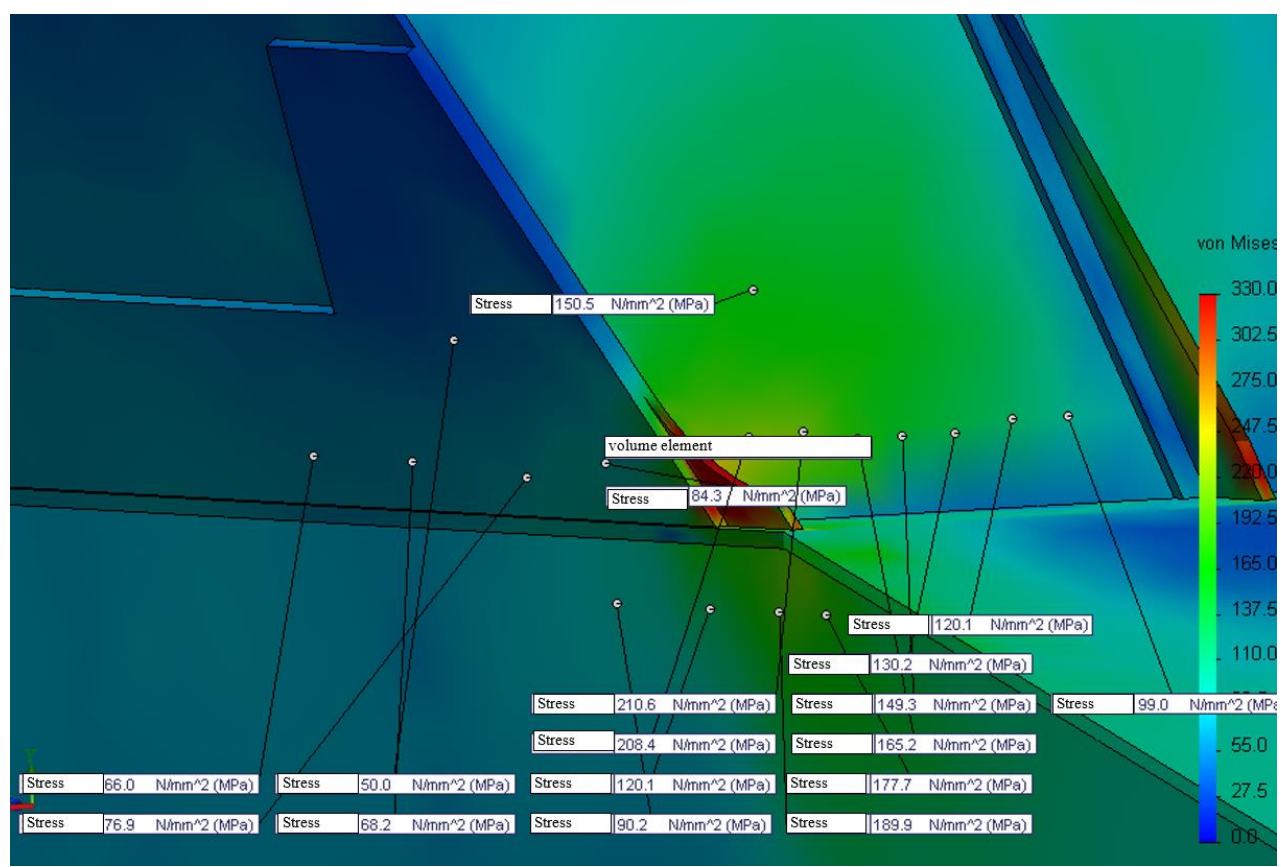

Fig. 9. Diagram of stress distribution taking into account reinforcement according to option 2 .

Option 3. The next step was installation of A-shaped pad on the inner sheet of the support.

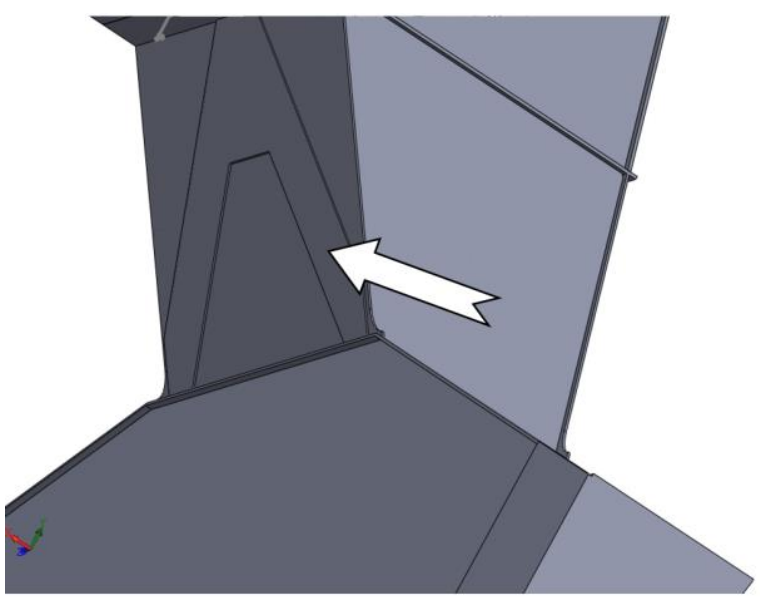

Fig. 10. Portal part with reinforcement according to option 3.

This solution allows local reduction of the stress values but it is completely useless for underloaded sections and it does not allow to improve distribution of loading flows and overall diagram of the stress-strain state. 


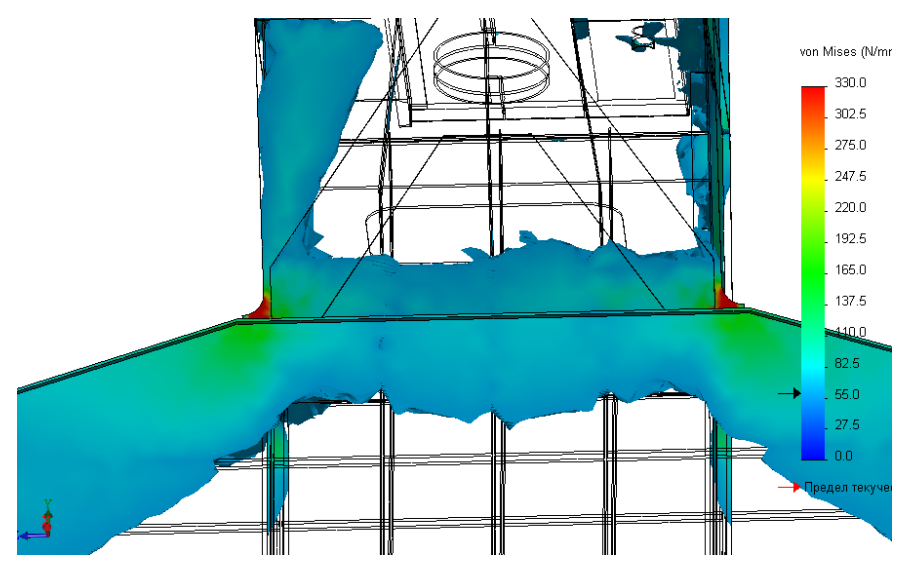

Fig. 11. Diagram of stress distribution taking into account reinforcement according to option 3 with excluded low-loaded elements.

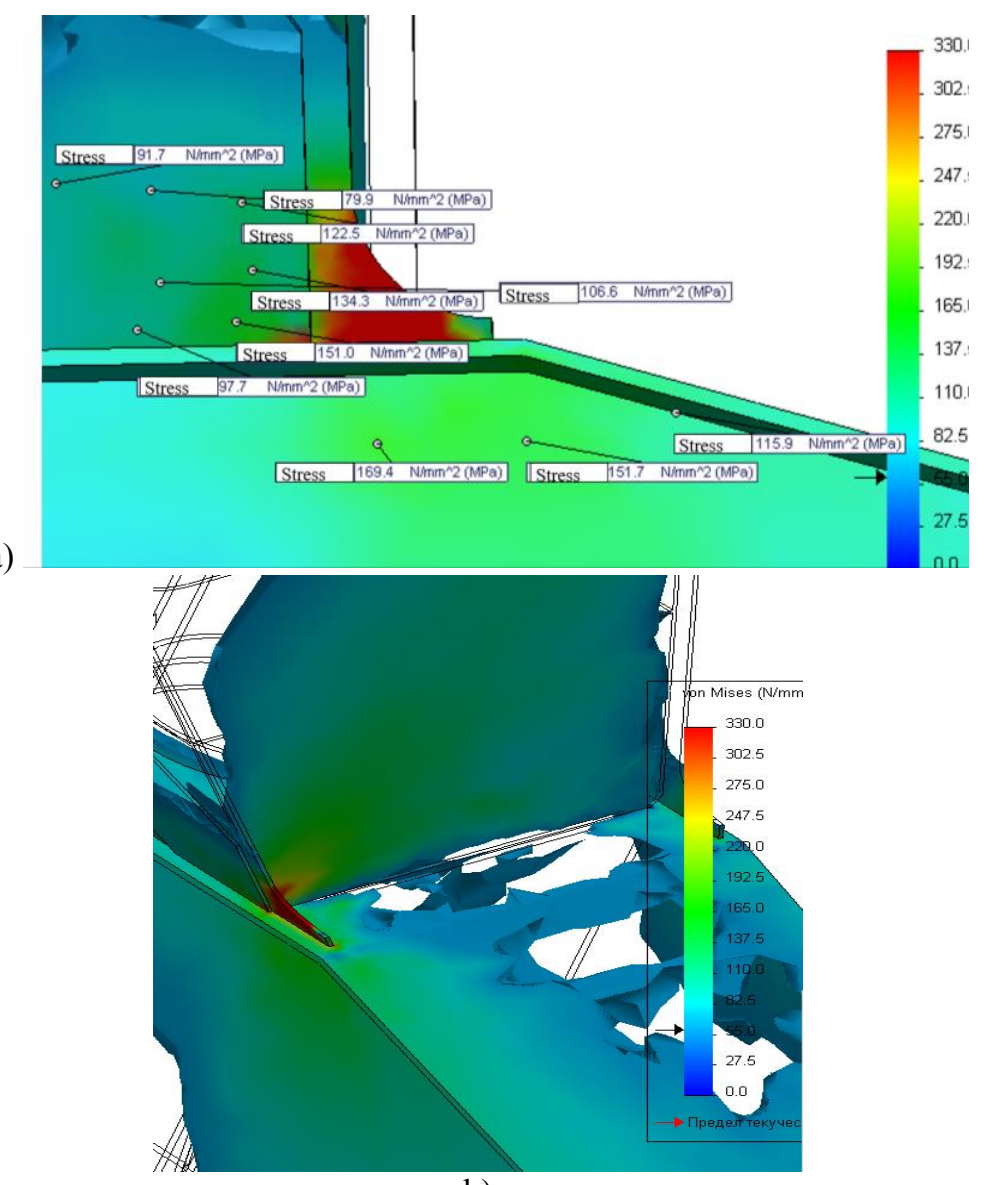

b)

Fig. 12. Diagram of stress distribution taking into account reinforcement according to option 3 with excluded low-loaded elements: $a, b$ are different angles of view. 
Option 4. Installation of stiffeners at junction of side support sheet to upper beam sheet.

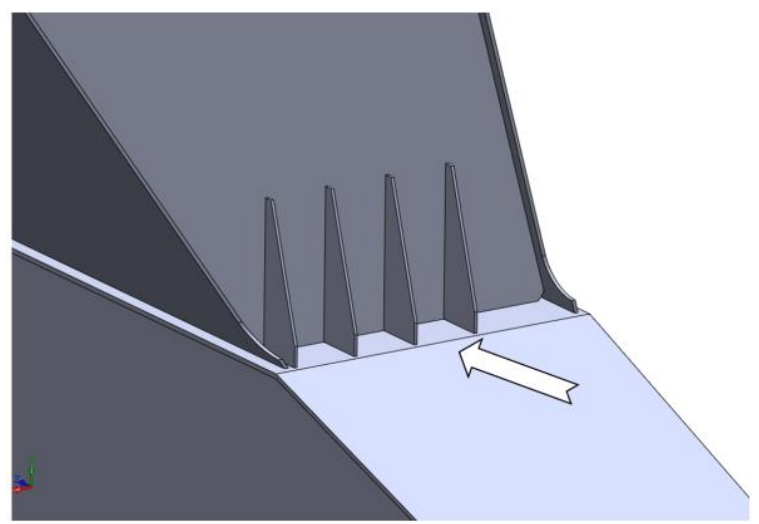

Fig. 13. Portal part with reinforcement according to option 4.

This solution allows to unload the metal structure, improve the distribution of stresses e.g., the maximum stresses have shifted to the outer wall of the support, to the upper belt of the beam.

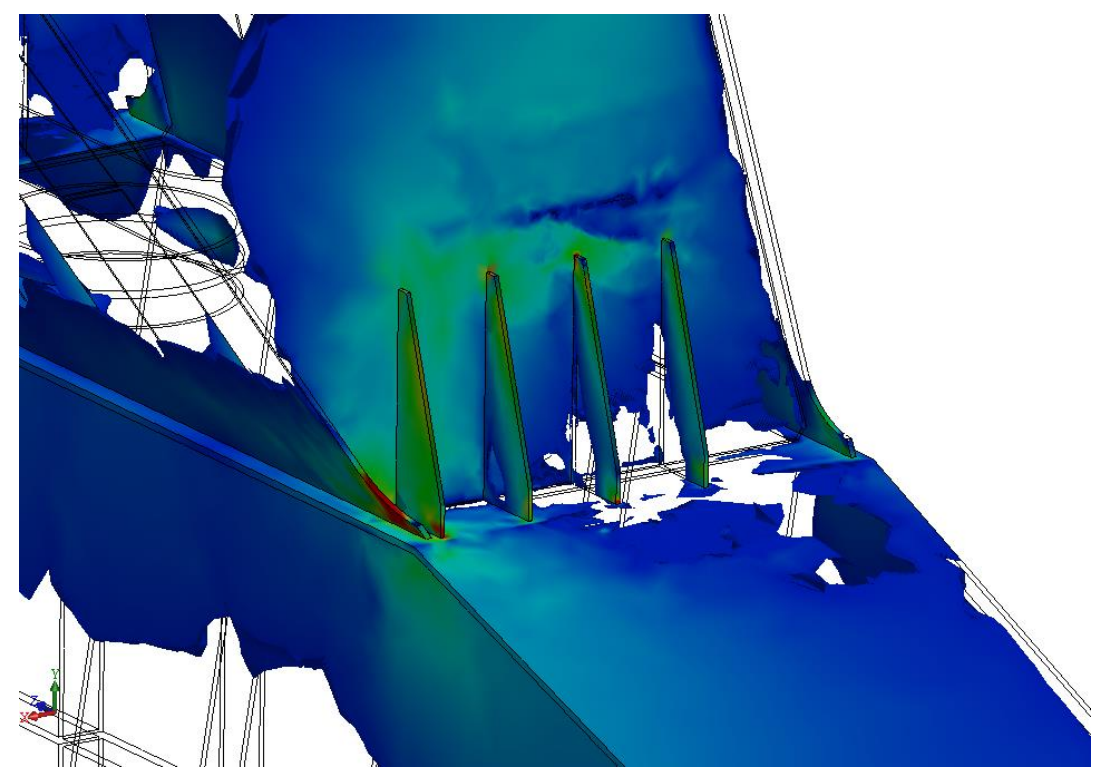

Fig. 14. Diagram of stress distribution taking into account reinforcement according to option 4 with excluded low-loaded elements. 
Option 5. Having saved the elements of option 4 (stiffeners on the side surface of the support) and by analogy with option 3 a U-shaped pad is installed on the inner wall of the support.

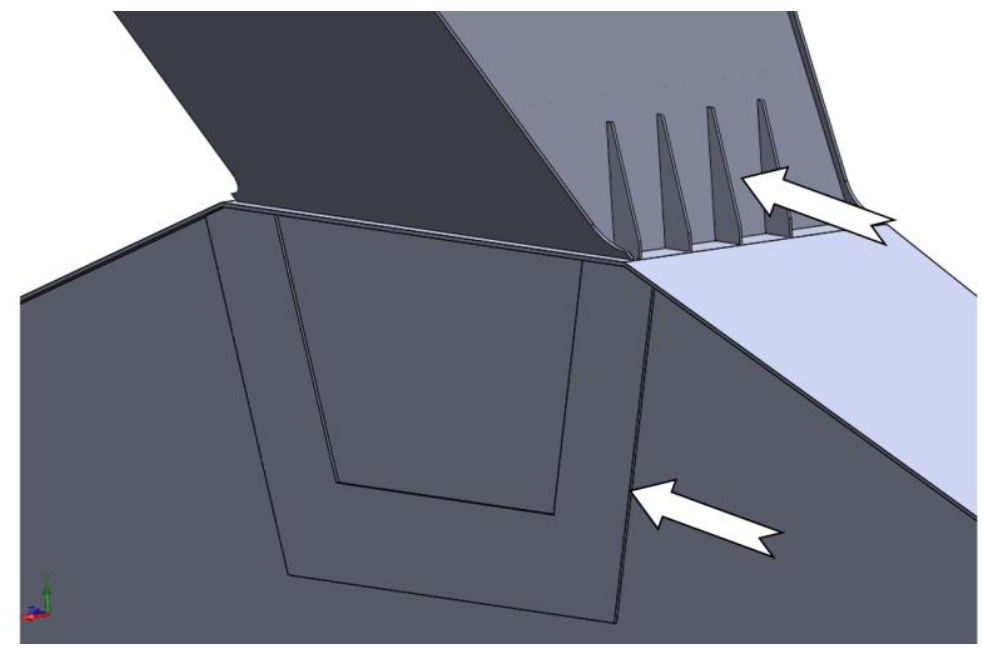

Fig. 15. Portal part with reinforcement according to option 5.

Obtained results are similar to the results of solutions 3 and 4 . As it can be seen from the diagram on figure below, the pad only allowed local reduction of stresses in the most loaded places.

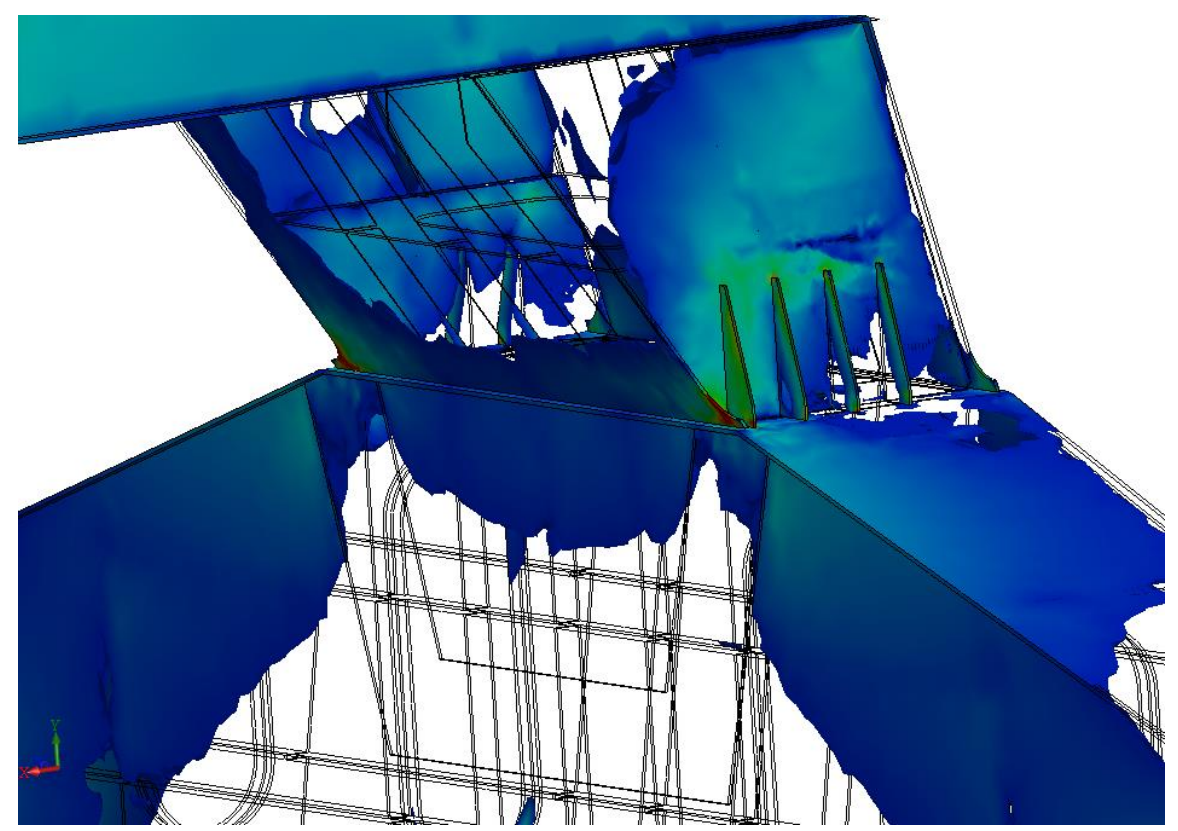

Fig. 16. Diagram of stress distribution taking into account reinforcement according to option 5 with excluded low-loaded elements.

Option 6. Installation of rib and stiffener on the side surfaces of the support (similar to solution 2) and installing the stiffeners on the inside at interface between the support and the 
beam ( 5 stiffeners are installed on the inner walls of the support and the beam opposite to their internal diaphragms).

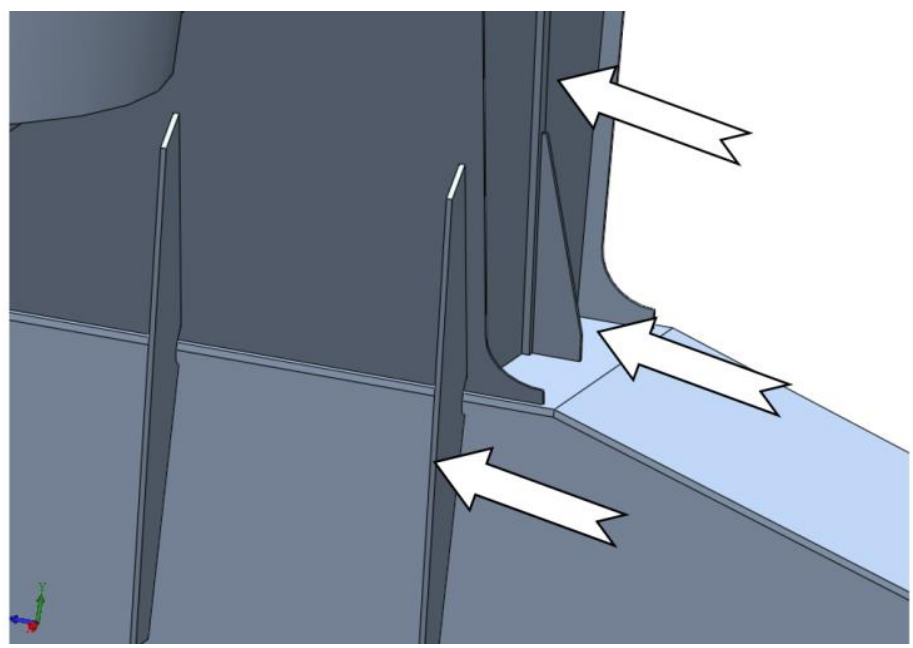

Fig. 17. Portal part with reinforcement according to option 6 .

Stiffeners on the inner side can reduce load on the walls of the support and beam, improve direction of loading flow. Stresses are distributed more uniformly.

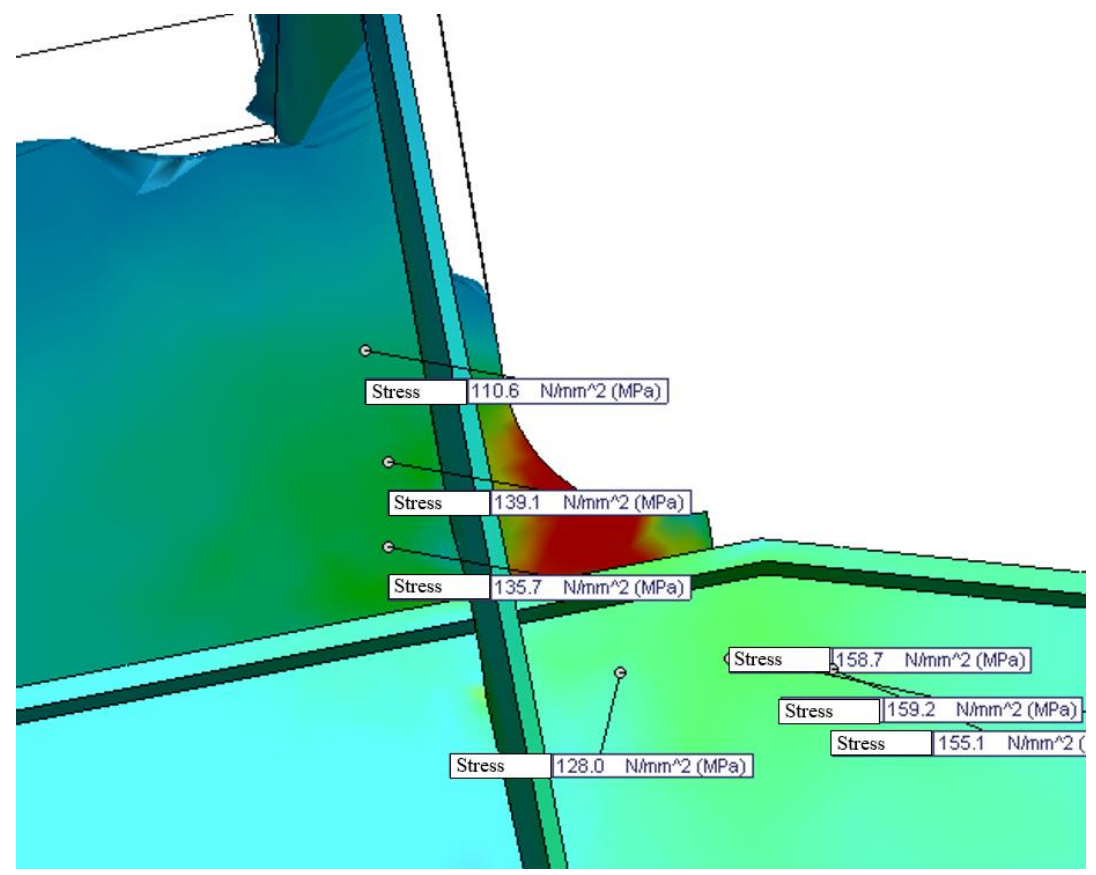

Fig. 18. Diagram of stress distribution and their values taking into account reinforcement according to option 6 with excluded low-loaded elements. 
Similar result is given by a vertical rib and a stiffener on the side wall of the support (similar to solution 2). However, as it can be seen below, from 5 internal stiffeners only two ones work such as outside left and right.

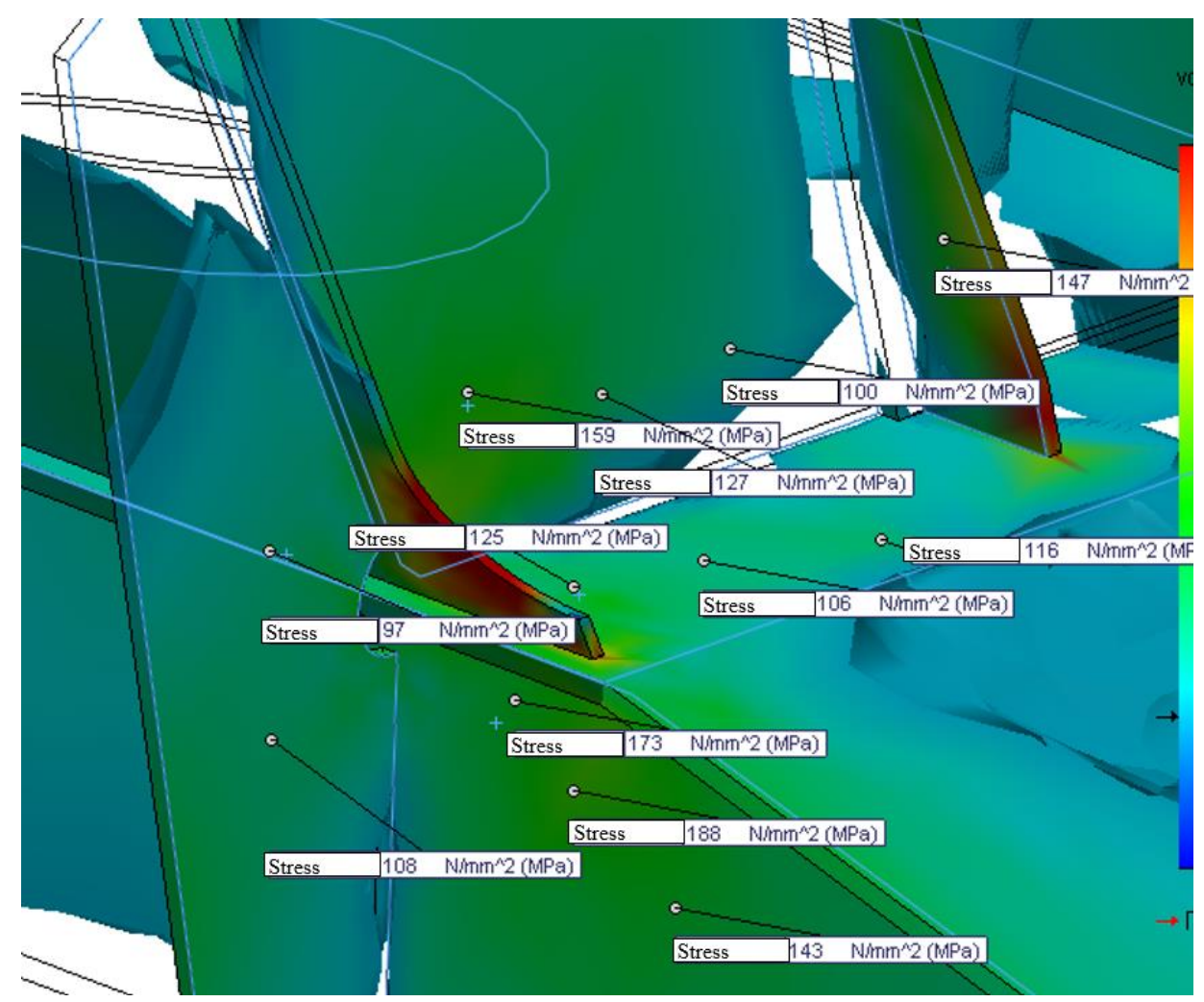

Fig. 19. Diagram of stress distribution and their values taking into account reinforcement according to option 6 with excluded low-loaded elements such as working stiffeners.

Option 7. Having saved elements of options 4 (stiffeners on the side surface of the support) and 2 (U-shaped pad on the inner wall of the support at junction of support and beam) a $\Pi$-shaped pad on the inner wall of the beam is additionally installed.

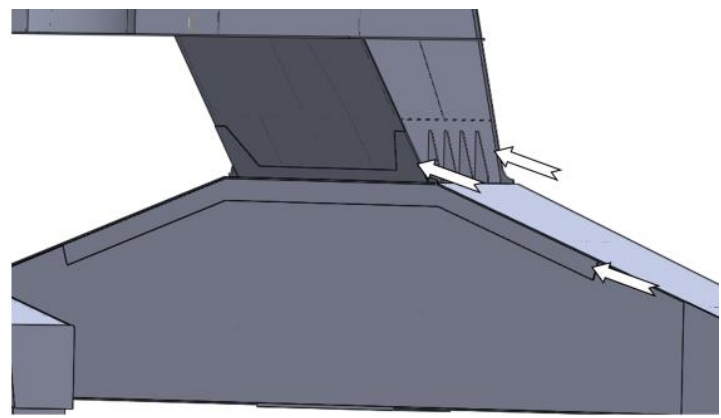

Fig. 20. Portal part with reinforcement according to option 7 .

As a result, retaining positive effects of solutions 2 and 4 local decrease of stresses at place of installation of the $\Pi$-shaped pad is additionally received. 


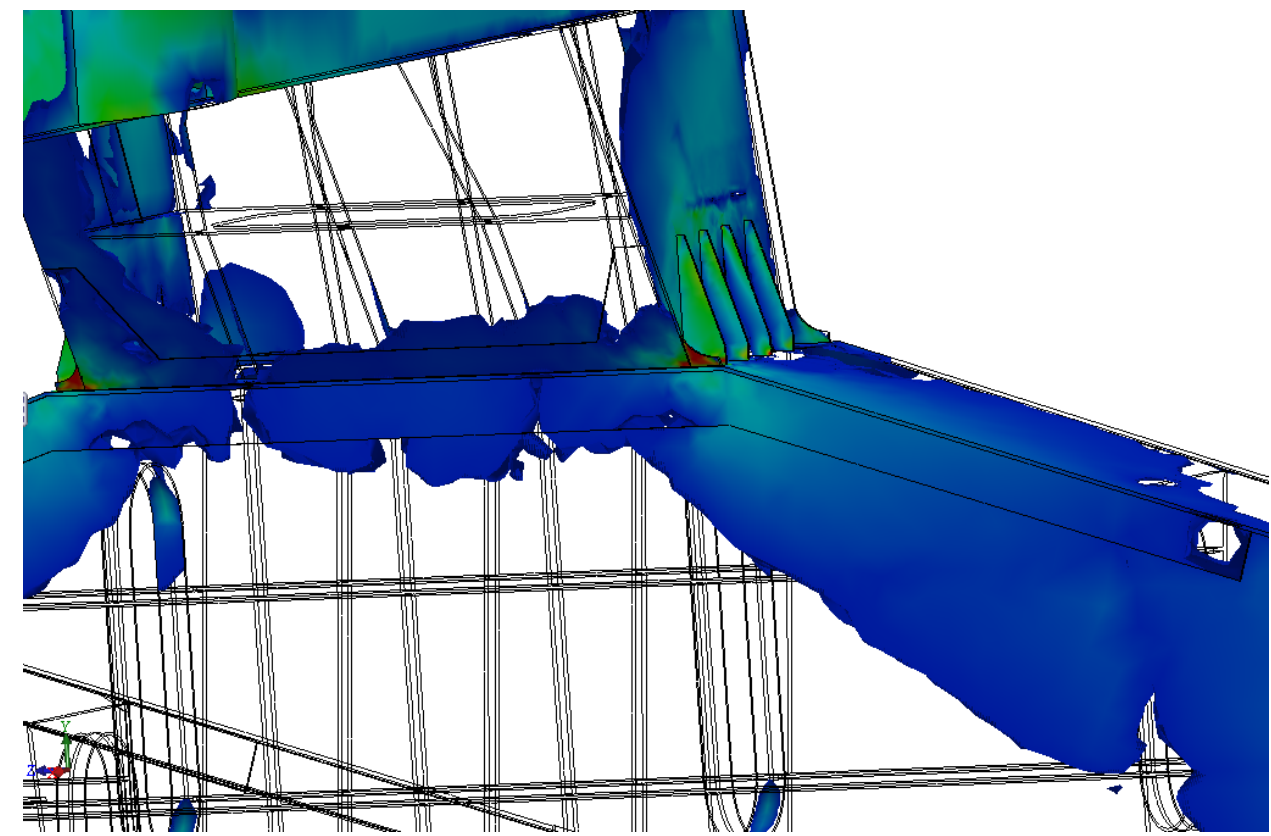

Fig. 21. Diagram of stress distribution taking into account reinforcement according to option 7 with excluded low-loaded elements.

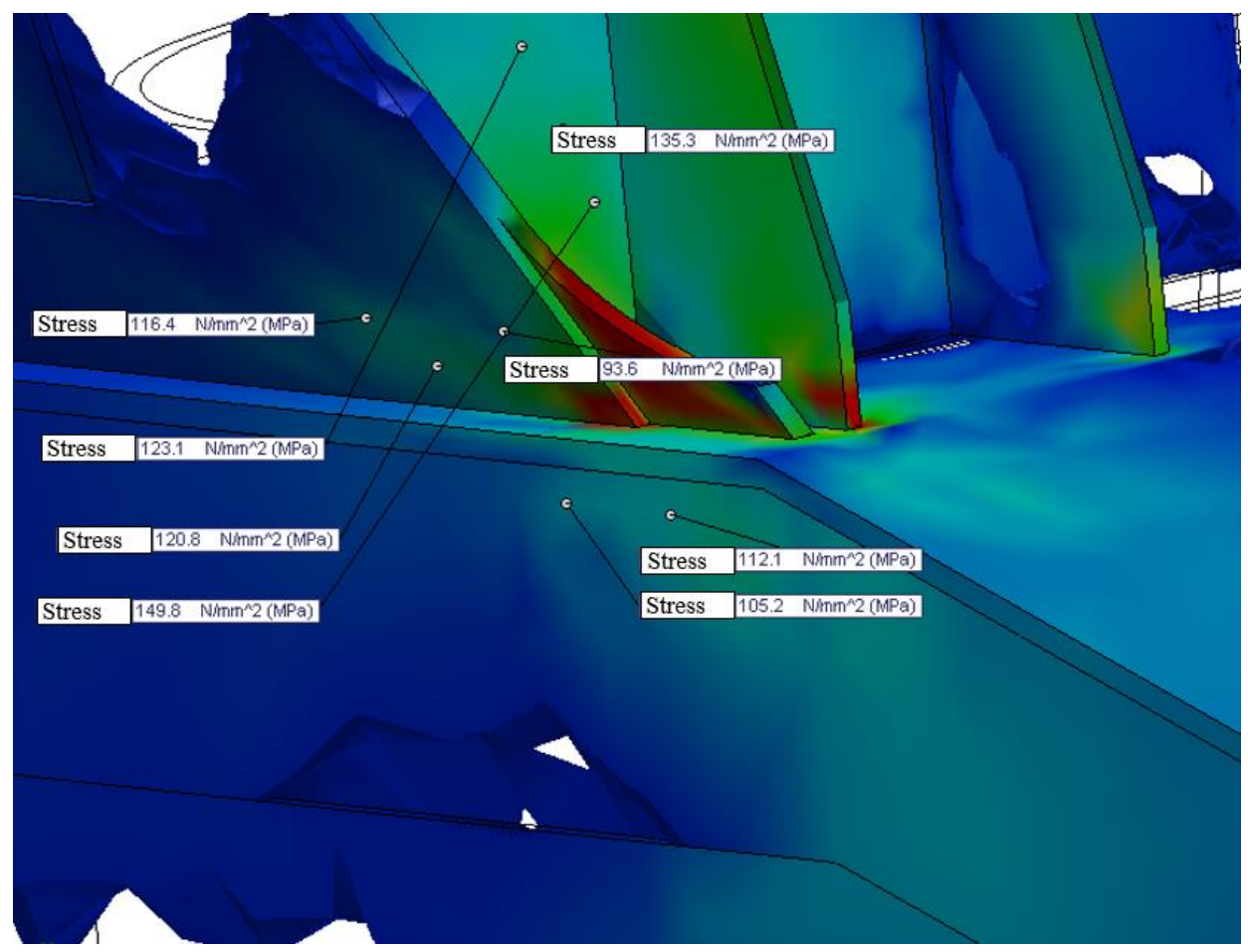

Fig. 22. Diagram of stress distribution and their values taking into account reinforcement according to option 7 with excluded low-loaded elements such as working stiffeners and pads. 
Option 8. Having saved elements of solution 4 (stiffeners on the side surface of the support) and taking into account effect obtained in solution 6 (installation of 5 stiffeners on the inner walls of the support and beams reciprocally to their internal diaphragms) 4 stiffeners were installed on the inner walls of the support and beams (two stiffeners on the left side and two ones on the right side).

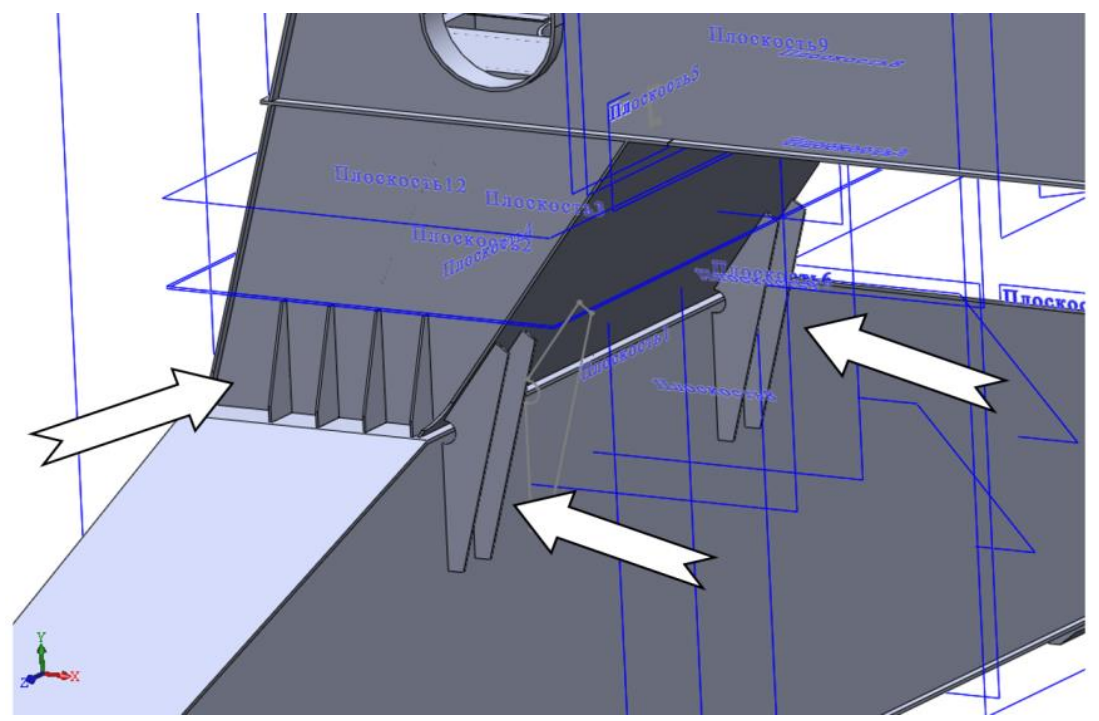

Fig. 23. Portal part with reinforcement according to option 8 .

This solution allowed to improve positive effects of previous solutions 4 and 6 . The internal stiffeners change stresses trajectory and reduce their values. Shift of the stiffeners closer to the side walls of the support allowed them to be included in work more efficiently.

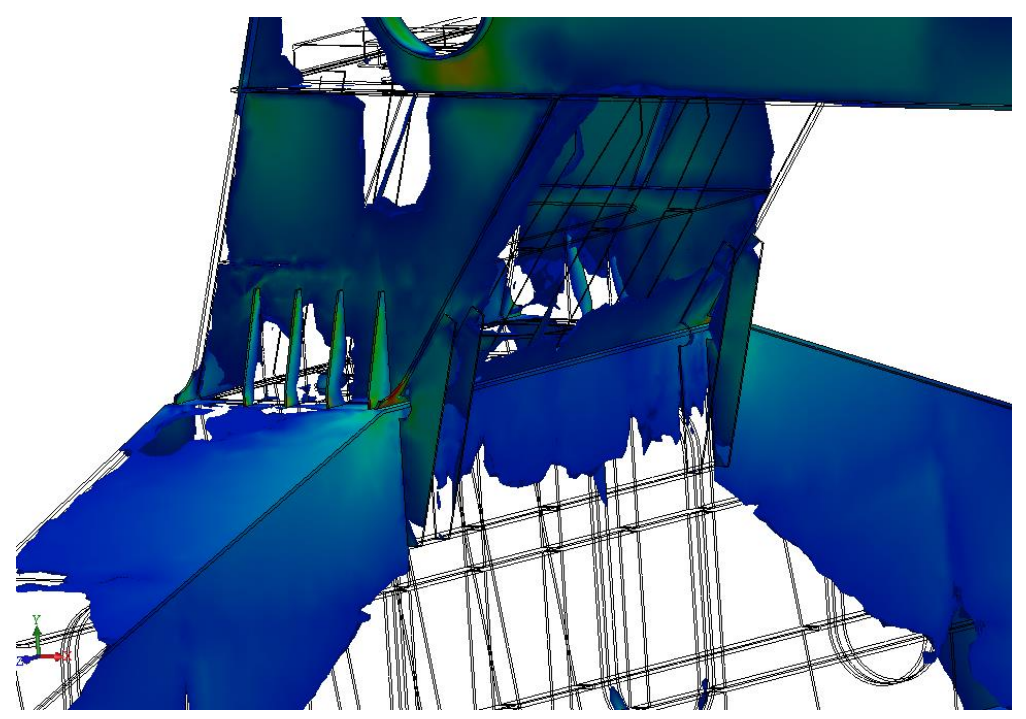

Fig. 24. Diagram of stress distribution taking into account reinforcement of option 8 with excluded low-loaded elements. 
a)

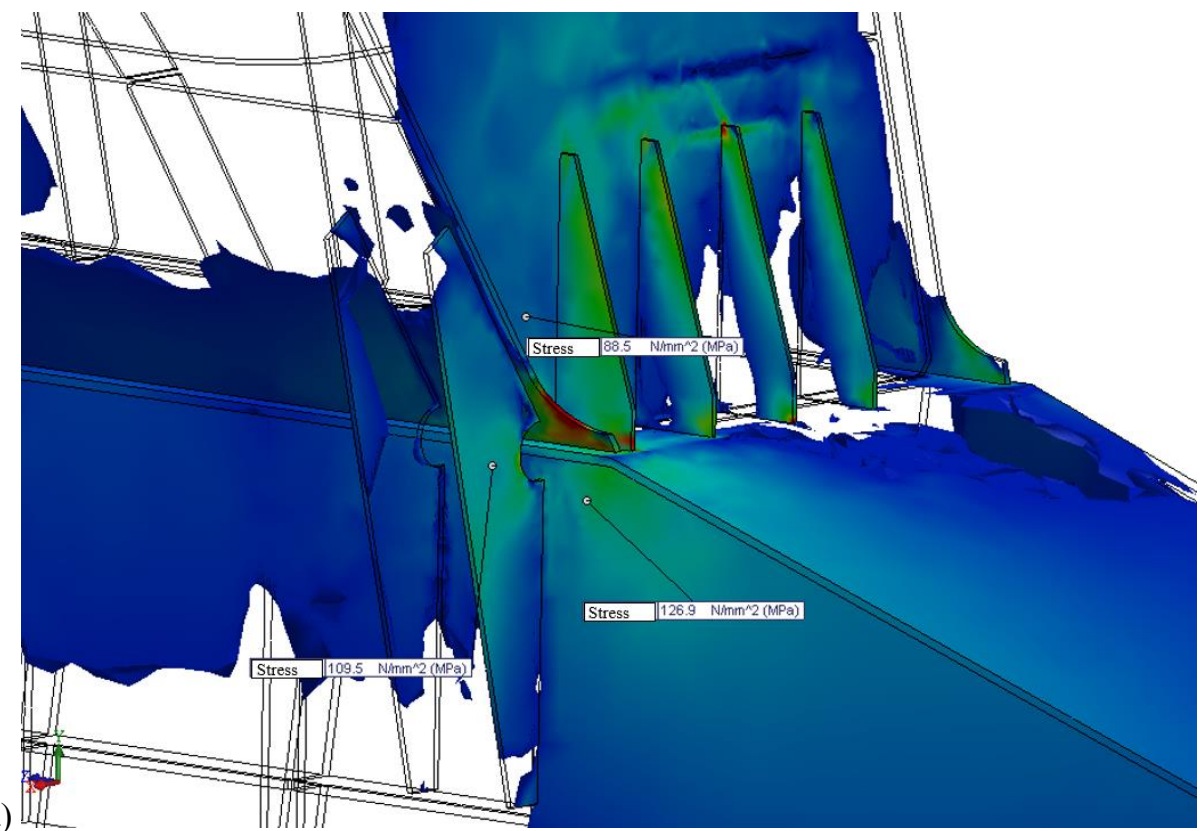

b)

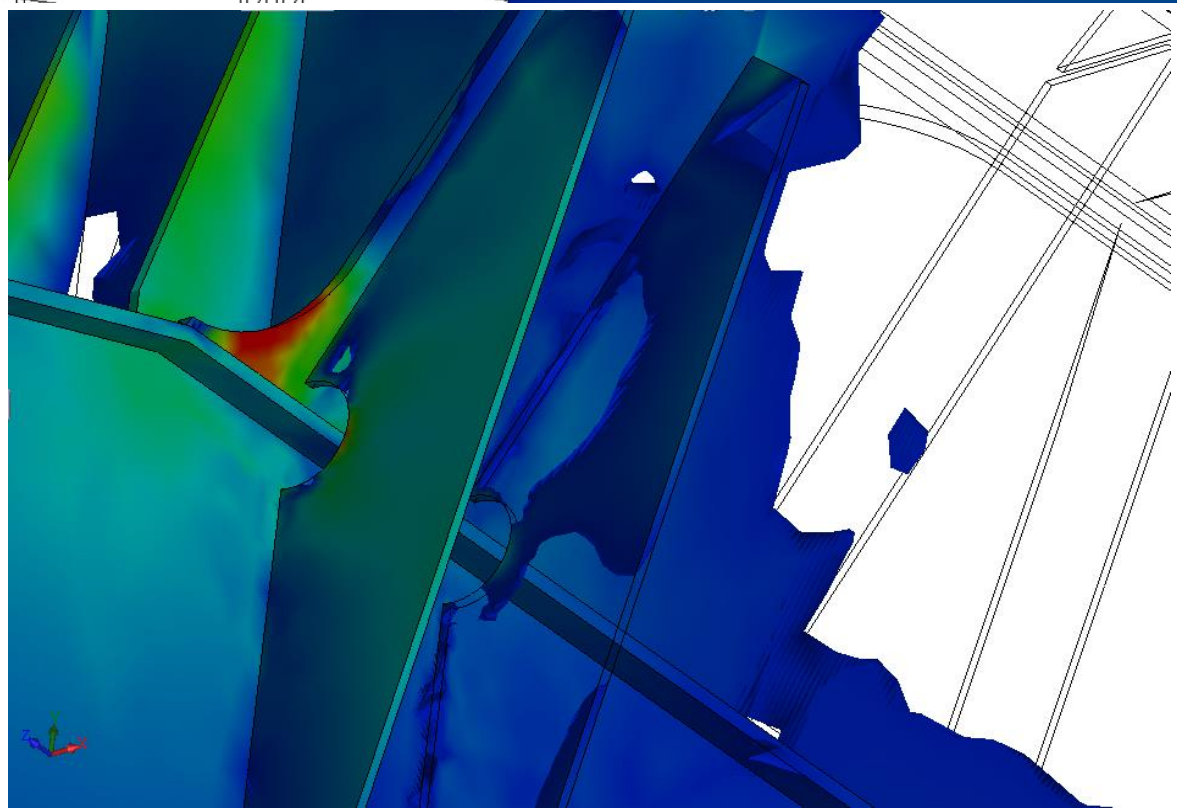

Fig. 25. Diagram of stress distribution taking into account reinforcement according to option 8 with excluded low-loaded elements: $a, b$ are different angles of view. 
Option 9. There is an attempt to change stress distribution starting from the girder in which inside there is a brace connecting the side wall and the lower belt.

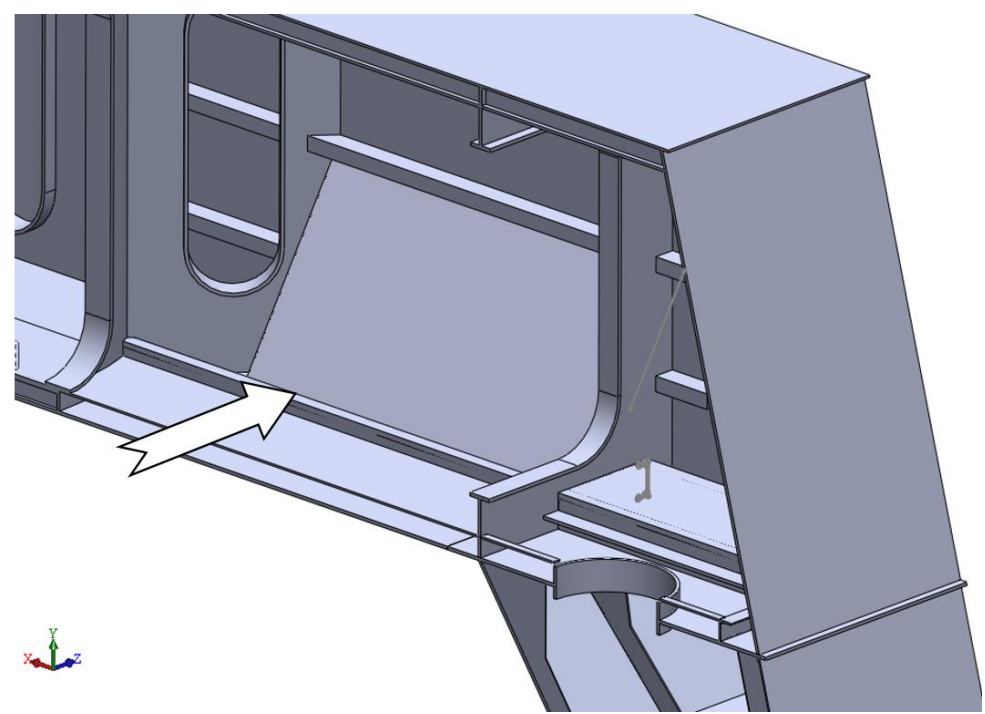

Fig. 26. Portal part with reinforcement according to option 9.

The brace itself (a sheet with a thickness of $8 \mathrm{~mm}$ ) turned out to be slightly loaded (less than $60 \mathrm{MPa}$ ), and did not introduce significant changes in stress distribution. A larger volume of the lower girder belt was included in the work. Stresses in the walls decreased.

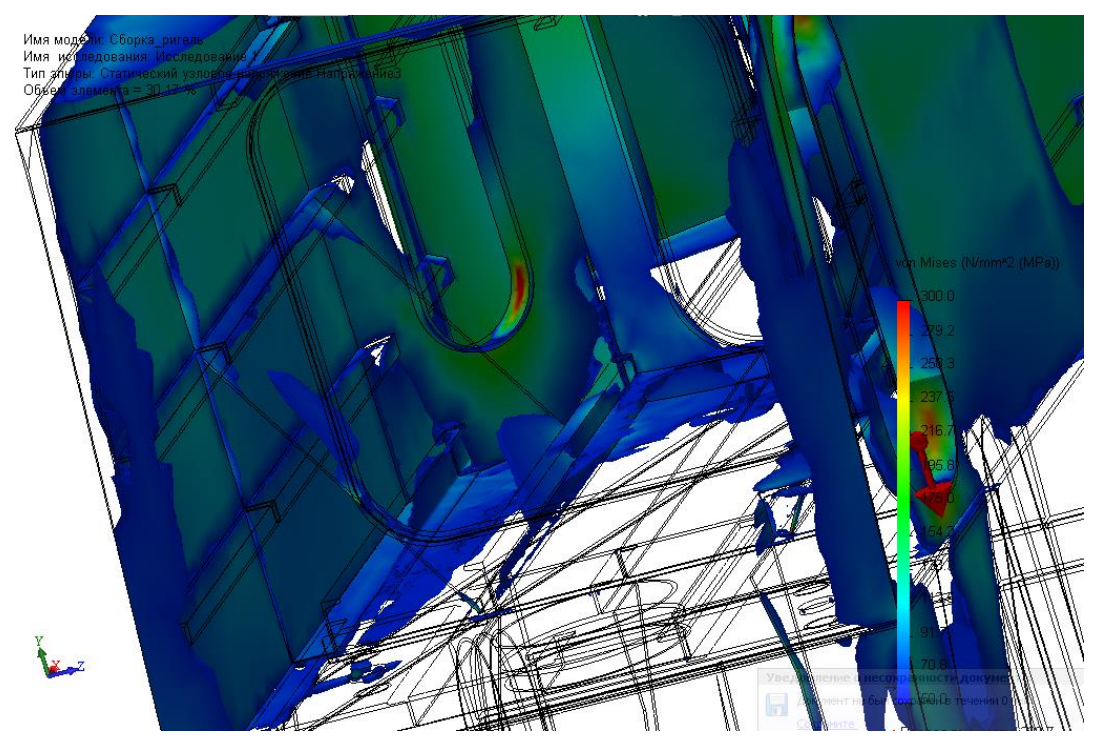

Fig. 27. Diagram of stress distribution taking into account reinforcement according to option 9 with excluded low-loaded elements.

Significant changes in other parts of the metal structure did not occur. 
a)
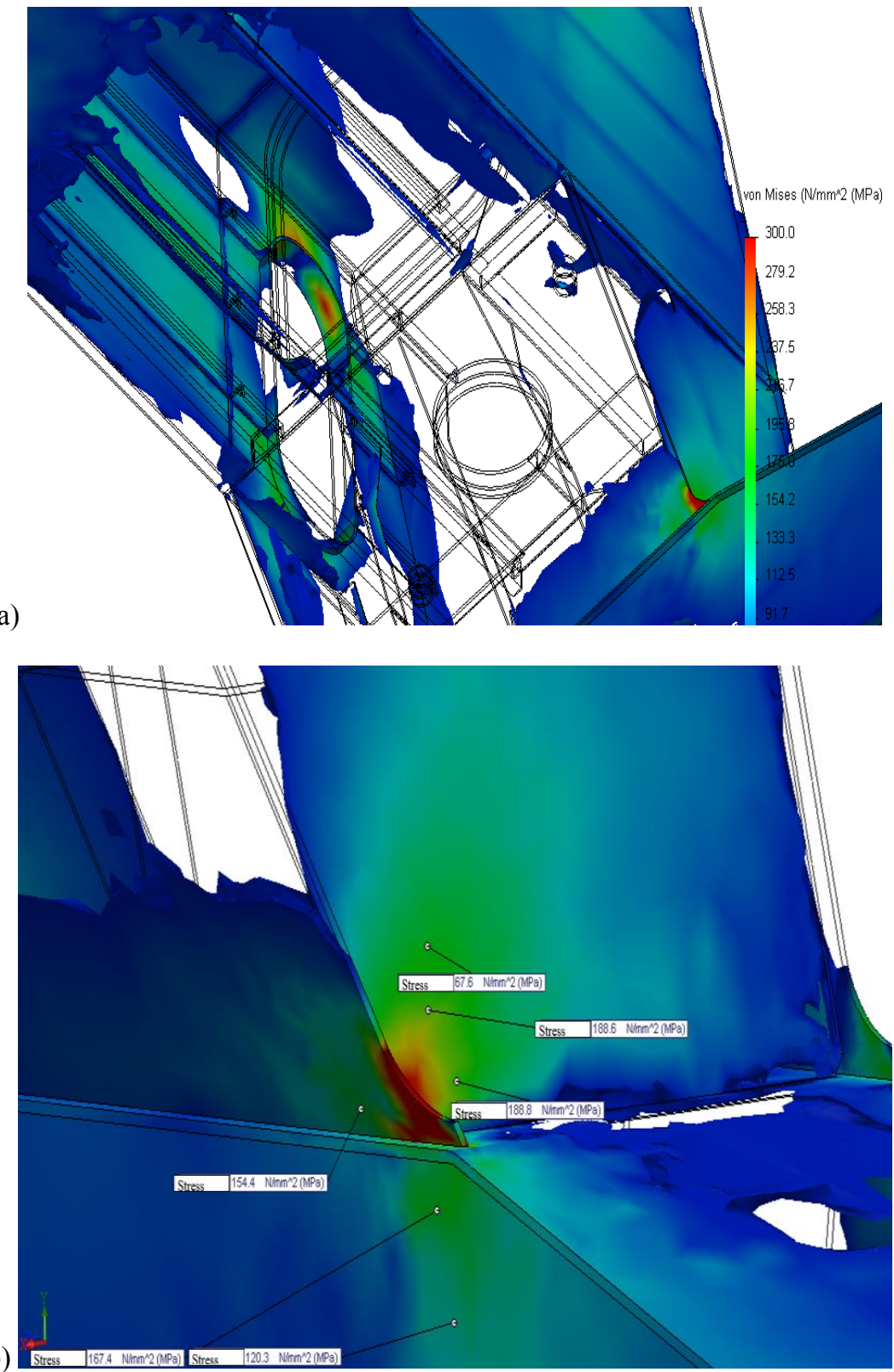

Fig. 28. Diagram of stress distribution taking into account reinforcement according to option 9 with excluded low-loaded elements: a, b are different angles of view. 
Option 10. Having saved elements of solution 7 (U-shaped pad installed on the inner wall of the support at junction of the support and the beam and $\Pi$-shaped pad installed on the inner wall of the beam), the stiffeners were replaced by pad that connected to the side wall of the support and to the upper belt of the beam.

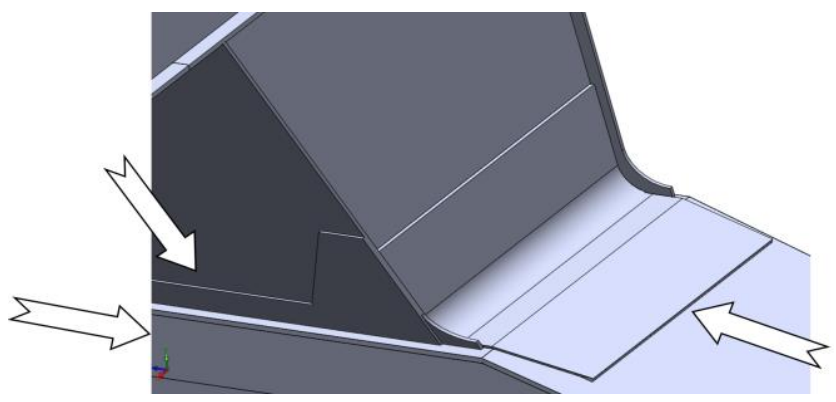

Fig. 29. Portal part with reinforcement according to option 10.

As it can be seen on fig. 30 this solution could not significantly change stress state of the side wall.

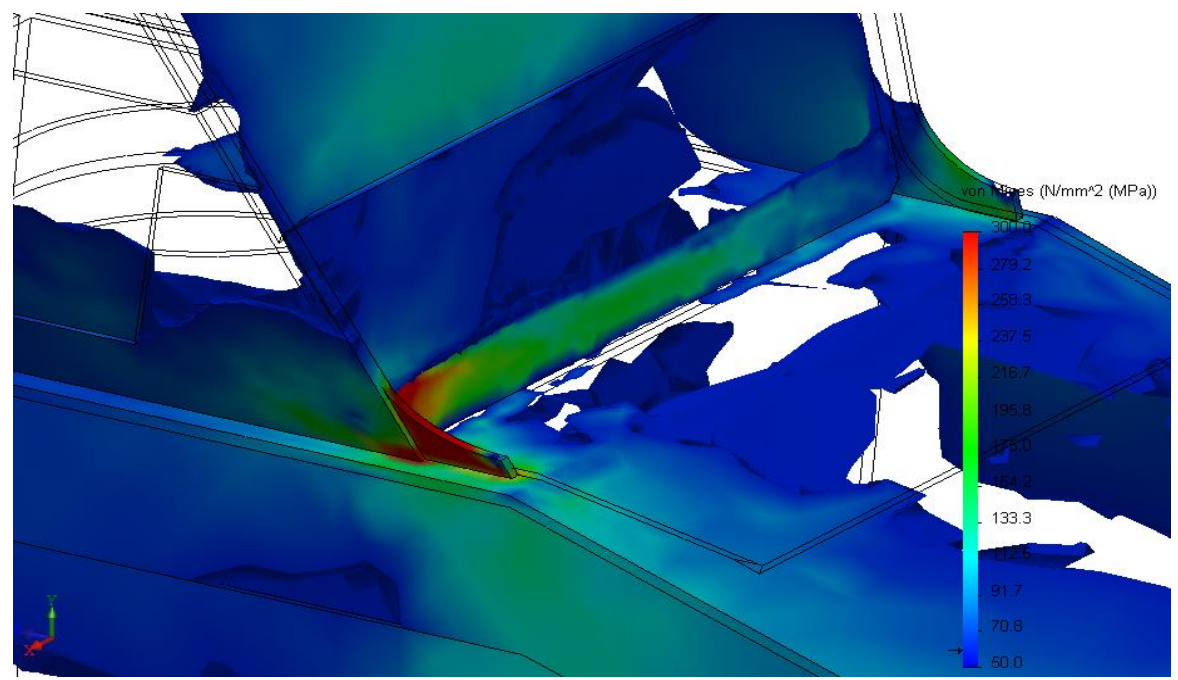

Fig. 30. Diagram of stress distribution taking into account reinforcement according to option 10 with excluded low-loaded elements.

Stresses decreased at the junction of the pad to the side wall and the upper belt. Stress distribution remains the same.

\section{Conclusions}

The paper proposes and implements a refined method for analyzing stress-strain state of the metal structure of the portal of portal crane 'Azovets'. Three-dimensional computer soliddeformable model was developed which together with 'SolidWorks' software and 'Simulation' application allowed to obtain:

1. patterns of distribution and change of stresses values in the portal metal structures (such diagrams as distribution of equivalent stresses, distribution of safety factor, linear displacements of elements, directivity of loading flows); 
2. patterns of changes of stresses distribution and their values based on structural and parametric synthesis of the portal metal structure.

Analysis of shown results allows to state following conclusions:

1. stresses in the model are distributed unevenly in all structural elements;

2. installation of additional ribs and pads in low-loaded places is ineffective because it does not allow changing direction of loading flows and reducing stresses in the model;

3. the most effective solutions for changing direction of loading flows and stress distribution in the model are installation of stiffeners on the side walls of the support, at junction of the inner walls of the support and the beam (two stiffeners on the left side and two ones on the right side);

4. reduction of stresses values in places of their maximum values is allowed by Ushaped pad installed on the inner wall of the support in place of junction of the support and the beam, $\Pi$-shaped pad on the inner wall of the beam;

5. to propose and apply in the model and on real object (portal crane 'Azovets') various options of constructive solutions to strengthen the portal.

By usage of obtained results according to the proposed methodology it is easy to make changes to design of metal structures at design stage and make full use of results of analysis of stress-strain state of metal structure. Structural and parametric synthesis can be used in order to design the optimal designs in terms of level and uniformity of stress distribution. Obtained results made it possible to modernize the design and reduce level of tension of the elements of portal crane 'Azovets' that results in improvement of its reliability and safety of operation. Parts with the maximum level of tension (identified as a result of the analysis) allow to make better quality surveys during operation of the crane because they require more attention. It should be noted that design methods of HTMs metal structures that exist today require development and refinement because they do not allow to have a clear picture of stress-strain state of structure as a whole. Software and technical characteristics of computers can significantly influence development process and increase accuracy of FEM models. There are still numerous methodological issues of application of topological optimization in design of HTMs metal structures to justify optimal forms of their elements and geometric characteristics of cross sections in order to minimize mass, ensure smooth loading flow, uniform stress distribution and reduce their values.

Further development of given above methodology will allow to develop simplified models for more efficient use of computer calculation time, software and its resources, apply software that implements topological optimization methods, and also, possibly, in the future, additive technologies $[20,21]$ in manufacture of HTMs metal structures, examples of which can already be seen at 'Caterpillar' company [22].

\section{Acknowledgement}

The reported study was funded by RFBR according to the research project №19-08-01252a 'Development and verification of inelastic deformation models and thermal fatigue fracture criteria for monocrystalline alloys'. The authors declare that there is no conflict of interest regarding the publication of this paper.

\section{References}

1. Y. Sahirov, V. Artiukh, V. Mazur, N. Vaynshtok, I. Reshetnikova, E3S Web of Conferences 110, 01049 (2019). DOI: https://doi.org/ 10.1051/e3sconf/201911001049 
2. V. Kukhar, N. Yelistratova, V. Burko, Y. Nizhelska, O.Aksionova, International Journal of Engineering \& Technology (UAE) 7(2.23), 216-220 (2018). DOI: https://doi.org/ 10.14419/ijet.v7i2.23.11922

3. V. Artiukh, V. Mazur, S. Kargin, L. Zakharova, MATEC Web of Conferences 170, 03028 (2018). DOI: https://doi.org/10.1051/ matecconf/201817003028

4. D.B. Efremov, A.A. Gerasimova, S.M. Gorbatyuk, N.A. Chichenev, CIS Iron and Steel Review 18, 30-34 (2019)

5. A.L. Sotnikov, V.N. Kireev, A.Yu. Orobtsev, et al., Steel in Translation 43 (12), 808814 (2013)

6. K.N. Solomonov. Materials Science Forum.704-705, 434-439 (2012)

7. D.A. Kitaeva, S.T. Pazylov, Y.I. Rudaev. Journal of Applied Mechanics and Technical Physics 57 (2), 352-358 (2016)

8. V. Kukhar, V. Artiukh, A. Prysiazhnyi, A. Pustovgar, E3S Web of Conferences 33, 02031 (2018). DOI: https://doi.org/ 10.1051/e3sconf/20183302031

9. A.L. Sotnikov, N.A. Rodionov, S.V. Ptukha. Analysis Of Mechanical Loading of the Hinges and Supports of the Mold Vibration Mechanism on a Continuous Caster. Metallurgist, V.58, Issue 9, pp.883-891 (2015)

10. Nabeel S. Gharaibeh, Mohammed I. Matarneh, V.G. Artyukh, Research Journal of Applied Sciences, Engineering and Technology 8(12), 1461-1464 (2014)

11. V. Artiukh, V. Mazur, A. Butyrin, Advances in Intelligent Systems and Computing, 692, 212-219 (2018).. DOI: https://doi.org/10.1007/978-3-319-70987-1_23

12. J. Fu, H. Li, L. Gao, M. Xiao, Computers \& Structures 212,.162-172 (2019). DOI: https://doi.org/ 10.1016/j.compstruc.2018.10.006

13. V. Mazur, V. Artiukh, Yu. Sagirov, S. Kuznezov, MATEC Web of Conferences 239, 01042 (2018). DOI: https://doi.org/10.1051/matecconf/201823901042

14. M.P. Bendsøe, O. Sigmund, Topology optimization - theory, methods and applications (Berlin Heidelberg, Springer-Verlag, 2004).

15. S. Boyd, Foundations and Trends ${ }^{\circledR}$ in Machine Learning 3 (1), 1-122 (2010). DOI: https://doi.org/10.1561/2200000016

16. S. Deng, Structural and Multidisciplinary Optimization 51 (5), 987-1001 (2015). DOI: https://doi.org/ 10.1007/s00158-014-1188-6

17. Junjian Fu, Hao Li, Liang Gao, Mi Xiao, Computers \& Structures 212, 162-172 (2019). DOI: https:// doi.org/10.1016/j.compstruc.2018.10.006

18. D.E. Grierson, S. Khajehpour, Recent advances in optimal structural design ASCE, 8196 (2002)

19. Zijun $\mathrm{Wu}$, Liang Xia, Shuting Wang, Tielin Shi, Computer Methods in Applied Mechanics and Engineering 345, 345-602 (2018). DOI: https://doi.org/10.1016/j.cma.2018.11.003

20. T. Wohlers, Wohlers report 2014: Additive manufacturing and 3D-printing state of the industry: Annual world-wide progress report (Wohlers Associates, 2014)

21. 5 things every manufacturer needs to know about $3 \mathrm{~d}$ printing [electronic resource]. Available at: https://www.aem.org/news/february-2018/5-things-every-manufacturerneeds-to-know-about-3d-printing/

22. Caterpillar opens 3D Printing \& Innovation Accelerator at Illinois HQ [electronic resource]. - Available at: https://identify3d.com/blog/caterpillar-opens-3d-printinginnovation-accelerator-at-illinois-hq/ 